Tropical Journal of Pharmaceutical Research May 2020; 19 (5): 1053-1058

ISSN: $1596-5996$ (print); 1596-9827 (electronic)

(C) Pharmacotherapy Group, Faculty of Pharmacy, University of Benin, Benin City, 300001 Nigeria.

\title{
Administration of S-allyl cysteine to neonatal rats modulates inflammatory biomarkers in high-fructose-fed rats in adulthood
}

\author{
Ademola O Ayeleso ${ }^{1,5}$, Busisani W Lembede ${ }^{2}$, Trevor T Nyakudya ${ }^{3}$, Ayodeji E \\ Adepoju ${ }^{1}$, Novel N Chegou ${ }^{4}$, Emmanuel Mukwevho ${ }^{5 *}$ \\ ${ }^{1}$ Department of Biochemistry, Faculty of Science, Adeleke University, PMB 250, Ede 232, Osun State, Nigeria, ${ }^{2}$ School of \\ Physiology, Faculty of Health Sciences, University of the Witwatersrand, 7 York Road, Parktown, Johannesburg 2193, South \\ Africa, ${ }^{3}$ Department of Physiology, School of Medicine, Faculty of Health Sciences, University of Pretoria, Pretoria 007, ${ }^{4}$ DST- \\ NRF Centre of Excellence for Biomedical Tuberculosis Research, South Africa Medical Research Council Centre for \\ Tuberculosis Research, Department of Biomedical Sciences, Division of Molecular Biology and Human Genetics, Faculty of \\ Medicine and Health Sciences, Stellenbosch University, Cape Town $8000,{ }^{5}$ Department of Biochemistry, Faculty of Natural and \\ Agricultural Science, North West University, Mafikeng Campus, Private Bag X2046, Mmabatho 2735, South Africa
}

*For correspondence: Email: emmanuel.mukwevho@nwu.ac.za; Tel: +27-18-389-2854

Sent for review: 20 October 2019

Revised accepted: 14 April 2020

\begin{abstract}
Purpose: To investigate the potential prophylactic effect of S-allyl cysteine (SAC), found in garlic (Allium sativum), against the development of apro-inflammatory status induced by diet in neonatal rats later on in adulthood.

Methods: Suckling Wistar rat pups (4-day-old; male $=21$ and female $=21)$ were randomly allocated to either of 3 groups and orally gavaged daily with the following treatments from postnatal day (PND) 6 - 20: group 1 (control) - $10 \mathrm{~mL} / \mathrm{kg}$ distilled water; group 2 - $10 \mathrm{~mL} / \mathrm{kg}$ of $20 \% \mathrm{w} / \mathrm{v}$ fructose solution (FS) and group 3 - $10 \mathrm{~mL} / \mathrm{kg}$ FS + SAC. The rat pups were weaned on PND 21, and given ad libitum access to standard rat chow and plain drinking up to PND 115. The rats were euthanized on PND 116 and

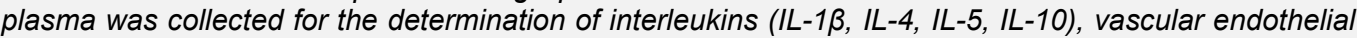
growth factor (VEGF) and monocyte chemotactic protein-1 (MCP-1)] using Bio-Plex Pro magnetic beadbased assays on Bio-Plex platform.

Results: Oral administration of FS during suckling increased significantly $(p<0.05)$ plasma concentrations of IL-5, MCP-1 and VEGF in adult male rats, and plasma MCP-1 in adult female rats. Neonatal oral administration of SAC prevented FS-programmed increase in pro-inflammatory cytokines $(p<0.05)$ later on in adulthood.

Conclusion: Oral administration of SAC during the neonatal period protected against FS-induced proinflammatory status and thus, could possibly be exploited as a prophylactic or intervention agent against a pro-inflammatory status induced by a high fructose diet.
\end{abstract}

Keywords: S-Allyl cysteine, Fructose solution, Cytokines, Pro-inflammatory chemokines, Neonatal programming

This is an Open Access article that uses a fund-ing model which does not charge readers or their institutions for access and distributed under the terms of the Creative Commons Attribution License (http://creativecommons.org/licenses/by/4.0) and the Budapest Open Access Initiative (http://www.budapestopenaccessinitiative.org/read), which permit unrestricted use, distribution, and reproduction in any medium, provided the original work is properly credited.

Tropical Journal of Pharmaceutical Research is indexed by Science Citation Index (SciSearch), Scopus, International Pharmaceutical Abstract, Chemical Abstracts, Embase, Index Copernicus, EBSCO, African Index Medicus, JournalSeek, Journal Citation Reports/Science Edition, Directory of Open Access Journals (DOAJ), African Journal Online, Bioline International, Open-J-Gate and Pharmacy Abstracts 


\section{INTRODUCTION}

Garlic (Allium sativum), a commonly consumed spice worldwide, is well-known as an effective 'natural' health beneficial agent in the treatment of a wide range of diseases [1]. It contains a water-soluble organosulphur s-allyl cysteine (SAC) (Figure 1) that possesses health-beneficial bioactivities [2]. S-allyl cysteine is derived from the amino acid cysteine in which an allyl group is added to the sulphur atom. Research has established that SAC possesses anti-oxidant, anti-diabetic, anti-obesogenic and antiinflammatory properties [2-4].

Adoption of sedentary lifestyles and the excessive consumption of unhealthy Westerntype hyper-calorific diets rich in fats and refined sugars [5] have been implicated as the main driver of increased prevalence of health outcomes associated with metabolic syndrome (MetS) such as obesity, non-alcoholic fatty liver disease (NAFLD) and [6]. Globally, there are over 600 million adults who are obese and 42 million children (under the age of five) who are overweight [7]. The Developmental Origins of Health and Diseases (DOHaD) is based on the fact that nutritional and environmental stimuli in the early developmental periods predisposes or protect organisms to develop metabolic disorders during subsequent developmental periods such as adolescence and adulthood [8,9]. During the early critical periods of development in life, the organisms have the ability to adapt at molecular, biochemical and cellular levels in response to sub-optimal stimuli which can be nutritional and environmental in origin [10]. The adaptations can persist permanently throughout life and can modify various physiological functions resulting in an increase in the vulnerability or resistance of developing metabolic disorders in either childhood or later on in adulthood [11].

Diet-induced metabolic disorders can either be hypothesized as the "single-hit" or a "double-hit" metabolic programming phenomenon. According to the single-hit hypothesis, a dietary intervention introduced in early-life can result in the onset of metabolic dysfunction or can serve as a programmer for the development of metabolic dysfunction in later life [12]. On the other hand, the "double-hit" hypothesis of metabolic programming is characterized by two dietary interventions; one early in life (first-hit) which programs the disease phenotype which only becomes apparent or manifests when a secondary dietary intervention (second-hit) is introduced in the subsequent stages of development in life [13]. Experimental animal and human studies have shown that direct neonatal exposure and indirect exposure through parents to sub-optimal diets such as diets that are high in fructose in the early stages of development modifies the expression of chemokine coding genes. Chemokines are involved in carbohydrate (glucose) and lipid metabolism and thus, can mediate the development and progression of metabolic disorders.

The therapeutic properties of SAC suggest that it may potentially be administered during suckling to program protection in early life against the development of adverse diet-induced health outcomes later on in adulthood. According to our knowledge, no studies have investigated the potential prophylactic effect of neonatal orally administered SAC in the neonatal period to program protection against neonatal highfructose diet-induced pro-inflammatory status in adulthood. This study investigated the effects of neonatal oral administration of SAC on plasma concentration of inflammatory biomarkers such as interleukins (IL-1 $\beta, I L-4, I L-5, I L-10)$, vascular endothelial growth factor (VEGF) and monocyte chemotactic protein-1 (MCP-1) in adult rats that were fed a high-fructose diet during suckling.<smiles>C=CCSC[C@H](N)C(=O)O</smiles>

Figure 1: Chemical structure of S-allyl cysteine

\section{EXPERIMENTAL}

\section{Animal housing and feeding}

This study was conducted on a total of 42 (4-dayold male $=21$ and female $=21$ ) suckling Wistar rat pups from five dams consisting of 8-12 rat pups. The dams and pups were housed in the Central Animal Service (rodent section) of the University of Witwatersrand, South Africa. The pups were allowed ad libitum suckling of their mother's milk throughout the pre-weaning stage. At post-weaning, the rats were housed individually in Perspex cages that had stainless steel mesh lids. The bedding was made up of clean wood shavings that was changed twice per week throughout the experimental period. Ambient temperature was maintained at $24 \pm 2$ ${ }^{\circ} \mathrm{C}$ with a 12-h light/dark cycle (lights on from 07:00 $\mathrm{h}$ to 19:00 h). Two days prior to the commencement of the experiments, the pups were acclimatised to the experimental housing conditions. All the experiments were conducted in compliance with international laws and policies set by the NIH Guide for the Care and Use of Laboratory Animals. Ethical clearance was 
granted by the Animal Research Ethics Committee (ethical clearance number: 2015/07/B) of the University of Witwatersrand, South Africa.

\section{Study design}

The pups were assigned to and orally gavaged with the treatments below:

Group 1 (Control) - $10 \mathrm{~mL} / \mathrm{kg}$ body mass distilled water.

Group 2 - $10 \mathrm{~mL} / \mathrm{kg}$ body mass of $20 \%$ (w/v) fructose solution (high-fructose diet; FS).

Group $3-10 \mathrm{~mL} / \mathrm{kg}$ body mass of FS + 150 $\mathrm{mg} / \mathrm{kg}$ body mass of SAC (FS + SAC).

The random allocation allowed for 7 male and 7 female pups per treatment group. During the preweaning period, the body weight of the pups was measured daily on an electronic scale (Snowrex Electronic Scale, Clover Scales Pty Ltd., Johannesburg, South Africa) in order to maintain a constant dose of the experimental treatments. The experimental treatments were administered as a single-bolus daily between postnatal day (PND) 6 and 20. The rat pups were weaned on PND21 and given ad libitum access to a standard rat chow diet and plain drinking water up to 115. On PND115, the rats were fasted overnight and then euthanised on PND 116 using an overdose intraperitoneal injection of sodium pentobarbital. Blood samples were collected via cardiac puncture into heparinised blood tubes (Becton Dickinson Vacutainer Systems Europe, Meylan Cedex, France) and centrifuged for 15 $\min$ at $4000 \times \mathrm{g}$ in a Sorvall $\mathrm{RT} \circledast 6000 \mathrm{~B}$ centrifuge (Pegasus Scientific Inc., Rockville, USA). Collected plasma samples were then subsequently stored at $-20{ }^{\circ} \mathrm{C}$ in micro-tubes until analysis.

\section{Determination of inflammatory biomarkers}

Bio-Plex Pro magnetic bead-based assays (BioRad Laboratories, USA) were used to measure plasma levels of inflammatory biomarkers namely interleukins (IL-4, IL-5, IL-10, IL-1 vascular endothelial growth factor (VEGF) and monocyte chemotactic protein-1 (MCP-1) using the Luminex technology. Briefly, plasma samples were added to a mixture of fluorescent magnetic beads bound with specific anticytokine primary antibodies which resulted to binding of cytokines to the bead with the corresponding antibody. The biotinylated anticytokine secondary antibodies were then added and made to bind to the cytokine-bead complex. Fluorescent phycoerythrin-conjugated streptavidin was then added after washing. The assays were read on the Bio Plex 200 platform (Bio Rad Laboratories, USA). The standard curve for all the analytes was between 3 to $12,000 \mathrm{pg} / \mathrm{mL}$. Bio-Plex manager software version 6.1 (Bio Rad Laboratories, USA) was used for bead acquisition and analysis.

\section{Statistical analysis}

All data were analysed using SPSS 22.0 system (IBM, Armonk, NY, USA), and presented as mean \pm standard error of mean (SEM). Differences in means between groups were determined using a one-way analysis of variance (ANOVA) and Student's t-test. Statistical significance was accepted when $p<0.05$.

\section{RESULTS}

\section{Effect of SAC on anti-inflammatory markers (IL-4 and IL-10)}

There were no significant $(p>0.05)$ differences in the IL-4 plasma concentration across all male $(4.05 \pm 0.57 \mathrm{pg} / \mathrm{mL}, 4.19 \pm 0.37 \mathrm{pg} / \mathrm{mL}$ and 4.87 $\pm 0.62 \mathrm{pg} / \mathrm{mL})$ and female $(4.43 \pm 0.20 \mathrm{pg} / \mathrm{mL}$, $4.77 \pm 0.61$, and $4.37 \pm 1.02 \mathrm{pg} / \mathrm{mL}$ ) treatment groups (Figure $2 \mathrm{~A}$ ). There were also no significant $(p>0.05)$ differences in the IL-10 plasma concentration across all male (45.52 \pm $6.66 \mathrm{pg} / \mathrm{mL}, 48.04 \pm 5.86 \mathrm{pg} / \mathrm{mL}$ and $50.47 \pm$ $6.33 \mathrm{pg} / \mathrm{mL})$ and female $(31.10 \pm 4.04 \mathrm{pg} / \mathrm{mL}$, $29.32 \pm 2.78 \mathrm{pg} / \mathrm{mL}$ and $36.80 \pm 2.68 \mathrm{pg} / \mathrm{mL})$ treatment groups (Figure $2 \mathrm{~B}$ ).
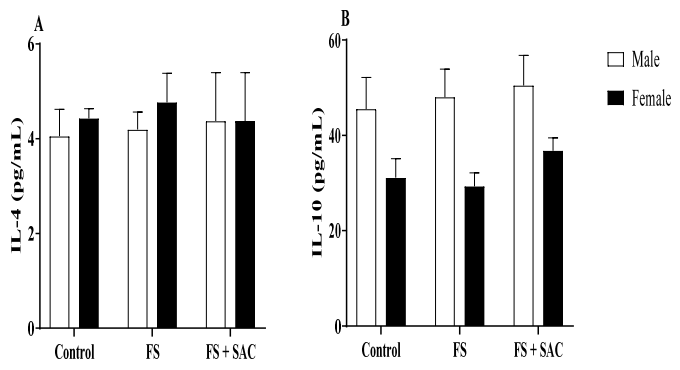

Figure 1: Effect of neonatal orally administered SAC on plasma IL-4 (A) and IL-10 (B) concentration in adult male and female rats that were treated with a a highfructose diet during the suckling period. Data are as mean \pm SEM; $\mathrm{n}=7$ per treatment. Control $=10 \mathrm{~mL} / \mathrm{kg}$ body mass distilled water; $\mathrm{FS}=10 \mathrm{~mL} / \mathrm{kg} 20 \%(\mathrm{w} / \mathrm{v})$ fructose solution; FS + SAC $=10 \mathrm{~mL} / \mathrm{kg} 20 \%(\mathrm{w} / \mathrm{v})$ fructose solution $+150 \mathrm{mg} / \mathrm{kg}$ body mass of SAC 
Effect of SAC on pro-inflammatory markers (IL-5, IL-1 $\beta$, VEGF and MCP-1)

The plasma concentrations of pro-inflammatory markers IL-5, IL-1 $\beta$, VEGF and MCP-1 are shown in Figure 3 and Figure 4. In male rats, neonatal administration $20 \%(\mathrm{w} / \mathrm{v})$ FS caused a significant increase $(p<0.05)$ in the plasma concentration of IL-5 $(64.27 \pm 5.37 \mathrm{pg} / \mathrm{mL})$ (Figure $3 \mathrm{~A})$ and VEGF $(15.87 \pm 8.71 \mathrm{pg} / \mathrm{mL}$ ) (Figure $4 \mathrm{~A}$ ). This FS-induced increase in IL-5 $(52.36 \pm 6.17 \mathrm{pg} / \mathrm{ml})$ and VEGF $(11.08 \pm 1.19$ $\mathrm{pg} / \mathrm{mL})$ was decreased $(p<0.05)$ by oral administration of SAC in the neonatal period (Figure $3 \mathrm{~A}$ and Figure $4 \mathrm{~A}$ ).
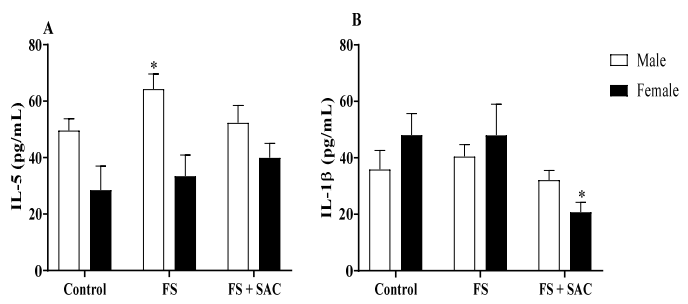

Figure 3: Effect of neonatal orally administered SAC on plasma IL-5 (A) and IL-1 $\beta$ (B) concentration in adult male and female rats were treated with a high-fructose diet during the suckling period. Data are mean \pm SEM; $\mathrm{n}=7$ per treatment. Control $=10 \mathrm{~mL} / \mathrm{kg}$ body mass distilled water; FS $=10 \mathrm{~mL} / \mathrm{kg} 20 \%(\mathrm{w} / \mathrm{v})$ fructose solution; FS + SAC $=10 \mathrm{~mL} / \mathrm{kg} 20 \%(\mathrm{w} / \mathrm{v})$ fructose solution $+150 \mathrm{mg} / \mathrm{kg}$ body mass of SAC; ${ }^{*} p<0.05$ vs control
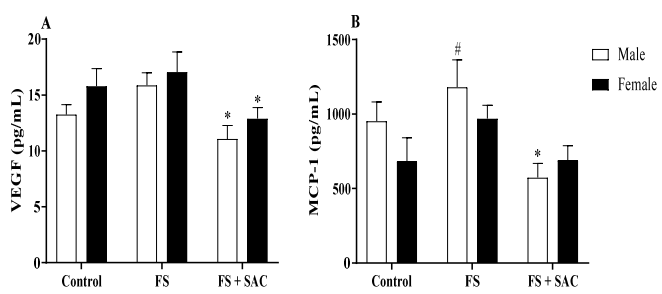

Figure 4: Effect of neonatal orally administered SAC on VEGF (A) and MCP-1 (B) plasma concentration in adult male and female rats were treated with a highfructose diet during the suckling period. Data are mean \pm SEM; $n=7$ per treatment. Control $=10 \mathrm{~mL} / \mathrm{kg}$ body mass distilled water; $\mathrm{FS}=10 \mathrm{~mL} / \mathrm{kg} 20 \% \mathrm{w} / \mathrm{v}$ fructose solution; FS + SAC $=10 \mathrm{~mL} / \mathrm{kg} 20 \%(\mathrm{w} / \mathrm{v})$ fructose solution $+150 \mathrm{mg} / \mathrm{kg}$ body mass of SAC; ${ }^{*} p<$ 0.05 vs FS; $\# p<0.05$ vs FS + SAC

When administered alone, $20 \% \mathrm{FS}$ had no effect $(p>0.05)$ on the plasma concentrations of IL-1 $\beta$ $(48.02 \pm 11.04 \mathrm{pg} / \mathrm{mL})$ (Figure 3B) and VEGF $(17.05 \pm 1.80 \mathrm{pg} / \mathrm{mL}$ ) (Figure $4 \mathrm{~A})$ in female rats. However, when the $20 \%$ FS was administered in combination with SAC, it decreased $(p<0.05)$ the plasma concentration of IL-1 $\beta(20.74 \pm 3.50$ $\mathrm{pg} / \mathrm{mL}$ ) (Figure $3 \mathrm{~B}$ ) and VEGF (12.89 \pm 0.99 $\mathrm{pg} / \mathrm{mL}$ ) (Figure 4A) in female rats. In both sexes, SAC significantly attenuated $(p<0.05)$ plasma concentrations of MCP-1 $(573.32 \pm 94.37 \mathrm{pg} / \mathrm{mL}$ and $689.24 \pm 98.90 \mathrm{pg} / \mathrm{mL}$ respectively) after 20 $\%$ FS neonatal administration (Figure $4 \mathrm{~B}$ ).

\section{DISCUSSION}

The therapeutic effects of S-allyl cysteine include but not limited to anti-cancer, anti-oxidant, antihyperlipidaemic, anti-diabetic and antiinflammatory activities [2-4]. The current study was designed to evaluate the long-term effects of neonatal oral administration of SAC on the inflammatory status of adult rats that were treated with a high-fructose diet, in the form of a $20 \%(w / v) F S$, during suckling. Findings from this study showed that the neonatal (suckling) period oral administration of FS during suckling resulted in elevated pro-inflammatory biomarkers in both adult male (IL-5, MCP-1 and VEGF) and female (MCP-1) rats. However, this increase in pro-inflammatory biomarkers was prevented when the FS was orally administered in combination with SAC during suckling. The oral administration FS and SAC individually or concomitantly during suckling had no effect on the anti-inflammatory biomarkers, IL-4 and IL-10, in both adult male and female rats.

Fructose metabolism occurs mainly in the liver and results in de novo lipogenesis [14]. This can translate into non-alcoholic fatty-liver disease, dyslipidaemia, obesity and impaired glucose homeostasis which are all associated with increased oxidative stress and a proinflammatory status [15]. Pro-inflammatory status is characterised by elevated plasma levels of pro-inflammatory chemokines such as IL-5, IL$1 \beta, V E G F$ and MCP-1 [15]. In the current study, the neonatal (suckling period) oral administration of FS resulted in increased plasma concentration of pro-inflammatory biomarkers namely IL-5, VEGF and MCP-1 in adult male rats. However, the oral administration of FS during suckling increased only the MCP-1 plasma concentration in adult female rats. These findings show that neonatal oral administration of FS during may have sexually dimorphic adverse programming effects that subsequently elicited the proinflammatory status in the male and female rats in adulthood. It has been reported that a proinflammatory status is associated with increased susceptibility of developing metabolic disorders associated with MetS such as obesity, nonalcoholic fatty liver disease [15]. 
Moreover, it has been reported that a proinflammatory status plays a significant role in to the pathogenesis and severity of these metabolic disorders $[16,17]$. Thus, it can be speculated that the administration of FS in the neonatal period may have increased the propensity of developing progressively more severe metabolic disorders in both adult male and female rats through upregulation of pro-inflammatory chemokines. It has been shown that male rat pups born to dams that were fed a high-fructose diet during pregnancy had upregulated IL1 $\beta$ mRNA expression when they were 10-days old [18]. Additionally, an association between maternal fructose consumption during gestation, early childhood fructose consumption and the onset of childhood asthma, which is an inflammatory disease has been reported [19]. Presently, the mechanisms by which early-life fructose consumption (maternal or neonatal) upregulates and or promotes pro-inflammatory status are not fully understood.

Interestingly, our findings show that the neonatal FS-induced elevation of IL-5, VEGF and MCP-1 in male rats and MCP-1 in female rats was attenuated by the oral administration of 150 $\mathrm{mg} / \mathrm{kg}$ of SAC during the neonatal period. These findings suggest that orally administered of SAC in the neonatal period exerted modulatory antiinflammatory effects in rats administered highfructose diet during suckling. The antiinflammatory properties of SAC have been recorded in a number animal studies. It has been shown that SAC prevented hexavalent chromium-induced hepatic-inflammation in rats by suppressing the expression of NF-kB, TNF- $\alpha$, and iNOS and increasing antioxidant enzymes in the liver [2]. On the other hand, a study using rats showed that the anti-inflammatory effects of SAC could potentially be exploited as prophylaxis against NSAID-induced gastric mucosal damage [20].

It has been reported that the mechanisms by which SAC exerts its anti-inflammatory effects include inhibition of COX-2 activity, histone deacetylation and reduction in the cellular and genetic expression of IL- $1 \beta$ and NFKB proteins in tissues [2]. Therefore, it is possible that orally administering SAC in the neonatal period protected the rats against fructose-induced proinflammatory status by reducing the expression of pro-inflammatory chemokines. Moreover, these findings reinforce and support our previous research which demonstrated that orally administering SAC during the neonatal period programmes protection against high-fructose diet-induced fatty-liver disease in later on in adulthood [21].

\section{CONCLUSION}

Findings from the current study demonstrate that the administration of dietary high-fructose solution $(20 \%(w / v))$, during suckling results in pro-inflammatory status that is manifest by elevation of pro-inflammatory chemokines in adulthood. However, neonatal oral administration of SAC conferred protection to the rats against fructose-induced pro-inflammatory status. Therefore, SAC could potentially be administered in early-life, as a prophylactic strategy to prevent the development of pro-inflammatory status in adulthood following early-life diet-induced programming.

\section{DECLARATIONS}

\section{Acknowledgement}

We thank staff of the Central Animal Services, University of the Witwatersrand for the animal husbandry and technical support.

\section{Conflict of interest}

The authors declare that no competing interest exists with regard to this work.

\section{Contribution of authors}

We declare that this work was done by the authors named in this article and all liabilities pertaining to claims relating to the content of this article will be borne by the authors. EM, BWL and AOA designed the project. TTN, BWL and AOA were involved in the collection of samples. BWL and NNC carried out the experiments. AEA, BWL, TTN and AOA wrote the manuscript. AEA did the statistical analysis. EM supervised all the work. All authors proof read and approved the manuscript.

\section{Open Access}

This is an Open Access article that uses a funding model which does not charge readers or their institutions for access and distributed under the terms of the Creative Commons Attribution License (http://creativecommons.org/licenses/by/ 4.0) and the Budapest Open Access Initiative (http://www.budapestopenaccessinitiative.org/rea d), which permit unrestricted use, distribution, and reproduction in any medium, provided the original work is properly credited. 


\section{REFERENCES}

1. Szychowski KA, Rybczyńska-Tkaczyk K, Gaweł-Bęben K, Świeca M, Karaś M, Jakubczyk A, Matysiak M, Binduga UE, Gmiński J. Characterization of active compounds of different garlic (Allium sativum L.) cultivars. Polish JFood Nutr Sci 2018; 68: 73-81.

2. Colín-González AL, Ali SF, Túnez I, Santamaría A. On the antioxidant, neuroprotective and anti-inflammatory properties of S-allyl cysteine: An update. Neurochem Int 2015; 89: 83-91.

3. Anandasadagopan S, Sundaramoorthy $C$, Pandurangan A, Nagarajan V, Srinivasan K, Ganapasam S. S-Allyl cysteine alleviates inflammation by modulating the expression of NF-KB during chromium (VI)-induced hepatotoxicity in rats. Hum ExpToxicol 2017; 36: 11861200.

4. Saravanan G, Ponmurugan P. Ameliorative potential of $S$-allylcysteine: Effect on lipid profile and changes in tissue fatty acid composition in experimental diabetes. Exp Toxicol Pathol 2012; 64: 639-644.

5. Pollock NK, Bundy V, Kanto W, Davis CL, Bernard PJ, Zhu H, Gutin B, Dong Y. Greater fructose consumption is associated with cardiometabolic risk markers and visceral adiposity in adolescents. JNutri 2012;142: 251257.

6. Steyn NP, Temple NJ. Evidence to support a food-based dietary guideline on sugar consumption in South Africa. BMC Public Health 2012;12: 1-8.

7. World Health Organisation (WHO). Global Status Report on non-communicable diseases. World Health Organisation 2014; https://www.who.int/topics/obesity/en/

8. Devaskar SU, Thamotharan M. Metabolic programming in the pathogenesis of insulin resistance. Rev Endocr Metab Disord 2007; 8(2): 105-113.

9. Léonhardt $M$, Lesage J, Croix D, Dutriez-Casteloot I, Beauvillain JC, Dupouy JP. Effects of perinatal maternal food restriction on pituitary-gonadal axis and plasma leptin level in rat pup at birth and weaning and on timing of puberty. Biol Reprod 2003;68: 390-400.

10. Hanley B, Dijane J, Fewtrell M, Grynberg A, Hummel S, Junien C, Koletzko B, Lewis S, Renz H, Symonds $M$, Gros M. Metabolic imprinting, programming and epigenetics-a review of present priorities and future opportunities. Br J Nutr 2010;104: S1-S25.
11. Fernandez-Twinn DS, Ozanne SE. Early life nutrition and metabolic programming. Ann NY Acad Sci 2010; 1212 : 78-96.

12. Tamashiro KLK, Moran TH. Perinatal environment and its influences on metabolic programming of offspring. Physiol Behav 2010;100: 560-566.

13. Stewart MS, Heerwagen MJ, Friedman JE. Developmental Programming of PediatriclNon-Alcoholic Fatty Liver Disease: Redefining the 'FirstHit'. Clin Obstet Gynecol 2013;56: 577-590.

14. Rutledge AC, Adeli K. Fructose and the Metabolic Syndrome: Pathophysiology and Molecular Mechanisms. Nutr Rev 2008; 65: S13-S23.

15. Pektas MB, Koca HB, Sadi G, Akar F. Dietary Fructose Activates Insulin Signaling and Inflammation in Adipose Tissue: Modulatory Role of Resveratrol. Biome Res Int 2016; 1-10.

16. Kootte $R$, Vrieze A, Holleman F, Dallinga-Thie GM, Zoetendal EG, De Vos WM, Groen BK, Hoekstra JBL, Stroes ES, Nieuwdorp M. The therapeutic potential of manipulating gut microbiota in obesity and type 2 diabetes mellitus. Diabetes 2012; 14: 112-120.

17. Song M, Schuschke DA, ZhouZ, Chen T, Shi X, Zhang J, Zhang $X$, Pierce WM, Johnson WT, Vos MB, McClain CJ. Modest fructose beverage intake causes liver injury and fat accumulation in marginal copper deficient rats. Obesity 2013; 21: 1669-1675.

18. Clayton ZE, Vickers MH, Bernal A, Yap C, Sloboda DM. Early Life Exposure to Fructose Alters Maternal, Fetal and Neonatal Hepatic Gene Expression and Leads to Sex-Dependent Changes in Lipid Metabolism in Rat Offspring. PLoS One 2015; 10: e0141962.

19. Wright LS, Rifas-Shiman SL, Oken E, Litonjua AA, Gold DR. Prenatal and Early Life Fructose, FructoseContaining Beverages, and Mid-childhood Asthma. Ann Am Thorac Soc 2018; 15: 217-224.

20. Park J-M, Han Y-M, Kangwan N, Lee S-Y, Jung M-K, Kim E-H, Hahm K-B. S-allyl cysteine alleviates nonsteroidal anti-inflammatory drug-induced gastric mucosal damages by increasing cyclooxygenase-2 inhibition, heme oxygenase-1 induction, and histone deacetylation inhibition. J Gastroenterol Hepatol 2014; 29: 80-92. doi:10.1111/jgh.12730.

21. Lembede BW, Erlwanger KH, Nkomozepi P, Chivandi E. Effect of neonatal orally administered S-allyl cysteine in high-fructose diet fed Wistar rats. J Dev Orig Health Dis2018; 9: 160-171. 